\title{
Correction to: Microbial community differentiation between active and inactive sulfide chimneys of the Kolumbo submarine volcano, Hellenic Volcanic Arc
}

Christos A. Christakis ${ }^{1,2}\left([)\right.$. Paraskevi N. Polymenakou ${ }^{1} \cdot$ Manolis Mandalakis $^{1}$ - Paraskevi Nomikou ${ }^{2}$. Jon Bent Kristoffersen ${ }^{1}$ - Danai Lampridou ${ }^{2} \cdot$ Georgios Kotoulas $^{1} \cdot$ Antonios Magoulas $^{1}$

Published online: 1 March 2018

(c) Springer Japan KK, part of Springer Nature 2018

Correction to: Extremophiles (2018) 22:13-27

https://doi.org/10.1007/s00792-017-0971-x

In the original publication there is a mistake in the supplementary material. The correct supplementary material is provided in this correction article.

The original article can be found online at https://doi.org/10.1007/ s00792-017-0971-x.

Electronic supplementary material The online version of this article (https://doi.org/10.1007/s00792-018-1017-8) contains supplementary material, which is available to authorized users.

Paraskevi N. Polymenakou polymen@hcmr.gr

1 Hellenic Centre for Marine Research, Institute for Marine Biology, Biotechnology and Aquaculture, 71500 Heraklion, Crete, Greece

2 Faculty of Geology and Geoenvironment, National and Kapodistrian University of Athens, Panepistimioupoli Zografou, 15784 Athens, Greece 